\title{
QUESTION OF UNIQUENESS OF RECOVERY OF POTENTIAL BY SPECTRUM IN THE INVERSE BORG LEVINSON PROBLEM WITH ROBIN BOUNDARY CONDITIONS
}

\author{
L.V. Smirnova, Nosov Magnitogorsk State Technical University, Magnitogorsk, \\ Russian Federation, smirnova20@bk.ru.
}

\begin{abstract}
The inverse Borg - Levinson problem with Robin boundary conditions, such that conditions for the uniqueness of the recovery of potential by spectrum are formulated for it, is considered in the paper. A similar problem, but with the Dirichlet boundary conditions, is enough studied. It is well known that the uniqueness of the recovery of potential is independent on removing of a finite number of spectral data in the inverse Borg - Levinson problem with Dirichlet boundary conditions. In the present paper we prove that the theorem, which was obtained for the Dirichlet boundary conditions, holds also for problem with Robin boundary conditions. To this end, we prove the theorems about the uniqueness of recovery of potential in the inverse Borg - Levinson problem with the Robin boundary conditions. Also we answer the following question. Suppose we know the nature of the asymptotic expansion of its eigenvalues. When this problem has a unique solution? The method to create a mathematical model of the recovery of potential in the inverse Robin problem is presented on the basis of it.
\end{abstract}

Keywords: inverse Borg - Levinson problem; eigenvalues; eigenfunctions; Robin boundary conditions.

\section{Introduction}

A problem of recovery of the operator by its given spectral characteristics is called an inverse problem of spectral analysis. Such characteristics can be spectra (with various boundary conditions), spectral function, scattering data, and others. The main idea of applications of inverse problems is the following: to measure certain quantities, which can be measured, and to obtain an information about the physical quantities on the basis of it. Consider the inverse problem of scattering on a potential. Here a physical quantity is the potential $q(x)$ of the Schrodinger equation, and the measured value is the scattering amplitude. In particular, some problems of quantum mechanics lead to problems of such type. For example, to determine of intra-atomic forces by given energy levels, i.e. by the spectrum, which can be found experimentally. Many inverse problems have not the only solution. For example, Borg showed that Sturm - Liouville operator generally is defined not uniquely by a single spectrum. Therefore, one of the most important problems is the uniqueness of the recovery of potential. A question about the identification of additional conditions, which ensure an uniqueness of the solution of the inverse problem, appears during solution of this problem.

For the first time the inverse problem for the Sturm - Liouville operator was set by V.A. Ambartsumian. In the simplest formulation, it was to identify the operator, when its spectrum is known. Further advances in the theory of inverse problems have been achieved by applying to the investigation of inverse problems the so-called operators of conversions. This method was developed in detail in the works of V.A. Marchenko, 
M.G. Crane, I.M. Gelfand, B.M. Levitan, L.D. Faddeev, M.G. Gasimov, Y.M. Berezanskii and others. They considered the theorems about the existence of the potential in the inverse problem of spectral analysis for ordinary differential equations. Note that the formulation of the inverse spectral problem was to find the potential of a given spectral function $\rho_{\alpha}(\lambda)$.

Spectral problem for the Laplace operator with potential was set by Y.M. Berezanskii. He proved that in the equation given in a finite or infinite bounded domain $G$ of threedimensional space,

$$
-\triangle u+c(p) u=\lambda u, \operatorname{Im} c(p)=0
$$

with the boundary condition

$$
\frac{\partial u}{\partial n}+\sigma(p) u=0
$$

where $\sigma(p)$ - continuous real function of point $p$ on the boundary $\Gamma$ of domain $G$, the spectral function $\vartheta(p, q, \lambda)(p, q \in I,-\infty<\lambda<\infty)$ uniquely determines the coefficient $c(p)$ in the class of piecewise analytic coefficients and boundary condition on a part of the boundary $\Gamma$, i.e. function $\sigma(p)$.

In 1990 M.I. Belishev [1] proposed an approach to solve multidimensional inverse problems of wave equation. This approach is based on the connection of boundary inverse problems with the boundary control problems. Here unknown factor (density), which is part of the wave equation, is restored during the solving of the problem of continuation of wave fields.

In 1988 A.I. Nachman, J. Sylvester , G. Uhlmann [12] published a paper about the proof of the multidimensional Borg - Levinson theorem. They considered the following problem:

$$
\left\{\begin{array}{l}
(-\triangle+q) u=\lambda u \text { в } \Omega, \\
\left.u\right|_{S}=0,
\end{array}\right.
$$

where $\Omega$ - bounded domain in $R^{n}(n \geq 2)$ with boundary $S$ of class $C^{\infty}$. They proved the uniqueness of the recovery of potential $q$ if all of eigenvalues and the values of the derivatives along the normal to the boundary $S$ of all eigenfunctions of this problem are known.

Subsequently, F.C. Ramm, T. Suzuki, G. Alessandrini, J. Sylvester presented similar results for other inverse problems of spectral analysis. The theorem about the uniqueness of the solution of inverse problems includes the values, which do not affect on the uniqueness of the recovery of potential. This fact become clear after paper written by H. Isozaki [5]. He proved a theorem about the uniqueness of the recovery of potential in the presented problem for the case, if there is not a finite number of spectral data.

The problem of uniqueness of the recovery of potential in the inverse problems of spectral analysis by inexact given spectral data was first studied by V.V. Dubrovskii, L.V. Smirnova [3, 4, 14-20]. So the question about the uniqueness of recovery of potential in the Neumann problem, if there is not an infinite number of eigenvalues and values of eigenfunctions on the boundary of a given domain, was resolved in paper [4]. Later V.V. Dubrovskii demonstrates the following. Let $\Omega$ be bounded domain in $\mathbb{R}^{2}$ with boundary $S$ of class $C^{2}$. Let a certain character of the asymptotic expansion of eigenvalues and certain additional conditions hold. Then the recovery of potential in inverse problems for Dirichlet and Neumann problems is unique. Possibilities of numerical methods for solving of spectral problems are considered in papers [1-6], written by S.I. Kadchenko and S.N. Kakushkin. 
The article discusses the inverse Borg - Levinson problem with Robin boundary conditions in statement of work by H. Isozaki [5]. In his article H. Isozaki concluded that the uniqueness of the recovery of potential is independent on removing of a finite number of spectral data in the inverse Borg - Levinson problem with Dirichlet boundary conditions. In the present paper we prove that the theorem, which was obtained for the Dirichlet boundary conditions, holds also for problem with Robin boundary conditions. Also we answer the following question. Suppose we know the nature of the asymptotic expansion of its eigenvalues. When the inverse problem with Robin boundary conditions has a unique solution? The method to create a mathematical model of the recovery of potential in the inverse Robin problem is constructed on the basis of it.

\section{Theorem about the Uniqueness of the Recovery of Potential by Incomplete Spectral Data}

Let $\Omega$ be bounded domain in $\mathbb{R}^{N}, N \geq 2$ with boundary $S$ of class $C^{\infty}$. Consider the Robin problem for real function $q \in C^{\infty}(\bar{\Omega})$, for real function $\delta \in C^{\infty}(S), \delta(x) \leq 0$ :

$$
\left\{\begin{array}{l}
(-\triangle+q) v=\lambda v \\
{\left.\left[\frac{\partial v}{\partial \nu}-\delta v\right]\right|_{S}=0}
\end{array}\right.
$$

where $\nu$ is inner normal to the surface $S, \lambda$ - is spectral parameter.

Problem (2) has not more than a countable number of eigenvalues $\mu_{1}, \mu_{2}, \mu_{3}, \ldots$, each of which has a finite multiplicity. Let $\mu_{1} \leq \mu_{2} \leq \mu_{3} \leq \ldots$ be eigenvalues of this boundary problem, taken with regard to their multiplicities, and $v_{1}, v_{2}, v_{3}, \ldots$ be corresponding them orthonormal eigenfunctions.

We denote a multiplicity of eigenvalue $\mu_{t}$ as $m_{t}$. Orthonormal eigenfunctions corresponding to $\mu_{t}$ denote by $v_{j t}, 1 \leq j \leq m_{t}$. These sets of functions are not uniquely defined.

Suppose

$$
E_{t}=\left\{\left.\left(v_{1 t}, v_{2 t}, \ldots, v_{m_{t} t}\right)\right|_{S}\right\}
$$

Two systems of eigenfunctions $\left\{u_{1 t}, u_{2 t}, \ldots, u_{m_{t} t}\right\},\left\{v_{1 t}, v_{2 t}, \ldots, v_{m_{t} t}\right\}$ are said to be equivalent, if there exists an orthogonal matrix $T$ such that

$$
\left.\left(u_{1 t}, u_{2 t}, \ldots, u_{m_{t} t}\right)\right|_{S}=\left.\left(v_{1 t}, v_{2 t}, \ldots, v_{m_{t} t}\right)\right|_{S} \cdot T .
$$

Obtained equivalence classes are denoted by $U_{t}$.

We introduce Dirichlet operator $D: L_{2}(S) \rightarrow L_{2}(S)$ by the equality

$$
D(\lambda, q) f=\left.v\right|_{S} .
$$

Here $f, v \in C^{\infty}(\bar{\Omega})$ are considered as an elements of $L_{2}(\Omega)$ and function $v \in C^{\infty}(\bar{\Omega})$ is a solution of Robin problem for

$$
\begin{aligned}
& \lambda \in C, \lambda \neq \mu_{t}(q), t=\overline{1, \infty}: \\
& \left\{\begin{array}{l}
(-\triangle+q) v=\lambda v \\
{\left.\left[\frac{\partial v}{\partial \nu}-\delta v\right]\right|_{S}=\frac{\partial f}{\partial \nu}-\delta f .}
\end{array}\right.
\end{aligned}
$$


We introduce $\langle f, g\rangle=\int_{S} f(x) \overline{g(x)} d S_{x}$.

Definition 1. A function $F$ is defined by an equality:

$$
F\left(\lambda, \omega, \theta ; q_{j} ; \delta\right)=\int_{S}\left(D\left(\lambda, q_{j}\right)\left(\frac{\partial \varphi_{\lambda, \omega}}{\partial \nu}-\delta \varphi_{\lambda, \omega}\right)\right)(x) \overline{\left(\frac{\partial \varphi_{\lambda,-\theta}}{\partial \nu}(x)-\delta \varphi_{\lambda,-\theta}(x)\right)} d S_{x}
$$

where $\varphi_{\lambda, \omega}(x)=\exp (i \sqrt{\lambda} \omega \cdot x), \lambda \in C /(-\infty ; 0), \omega \in S^{N-1}, \theta \in S^{N-1}$.

To prove the theorems about the uniqueness of recovery of potential for Robin boundary problem we need the following lemma, which can be proved by Green formula.

Lemma 1. For function $F$ the following equality holds:

$$
\begin{gathered}
F\left(\lambda, \omega, \theta ; q_{j}\right)=-\frac{\lambda}{2}(\theta-\omega)^{2} \int_{\Omega} \exp (-i \sqrt{\lambda}(\theta-\omega) x) d x-\int_{\Omega} \exp (-i \sqrt{\lambda}(\theta-\omega) x) q_{j}(x) d x- \\
-\int_{S} \delta(x) \exp (-i \sqrt{\lambda}(\theta-\omega) x) d S_{x}-\int_{\Omega} q_{j}(x) \cdot\left(-\triangle+q_{j}-\lambda\right)^{-1}\left(q_{j} \varphi_{\lambda, \omega}\right)(x) \cdot \overline{\varphi_{\lambda,-\theta}(x)} d x .
\end{gathered}
$$

Consider the sequences of the form

$$
\begin{gathered}
\sqrt{l_{n}}=n+i, \omega_{n}=c_{n} \eta-\xi(2 n)^{-1}, \\
\theta_{n}=c_{n} \eta+\xi(2 n)^{-1}, c_{n}=\left(1-|\xi|^{2}\left(4 n^{2}\right)^{-1}\right)^{\frac{1}{2}}, n=1,2, \ldots,
\end{gathered}
$$

where $\eta \in S^{N-1}$ and $\xi$ is an arbitrary fixed element $R^{N}, \xi \neq 0$, and $(\eta, \xi)=0$. In these sequences we obtain the limit equality:

$$
\lim _{n \rightarrow \infty} F\left(l_{n}, \theta_{n}, \omega_{n} ; q\right)=-\frac{|\xi|^{2}}{2} \int_{\Omega} \exp (-i x \cdot \xi) d x+\int_{\Omega} \exp (-i x \cdot \xi) q(x) d x .
$$

In the future we will use (4) to prove theorems about the uniqueness of the recovery of potential in the Robin problem.

Consider problem (2) with potentials $q_{1}, q_{2} \in C^{\infty}(\bar{\Omega})$. Let us prove the theorem..

Theorem 1. Let $q_{1}, q_{2}$ be real functions of $C^{\infty}(\bar{\Omega})$ such that for some natural number $T>0$ for the Robin problems (1) the following conditions holds:

1. $\left.\forall t \in N U_{t}\left(q_{1}\right)\right|_{S}=\left.U_{t}\left(q_{2}\right)\right|_{S}$;

2. $\exists T \in N \forall t \geq T \mu_{t}\left(q_{1}\right)=\mu_{t}\left(q_{2}\right)$.

Then $q_{1}(x)=q_{2}(x)$ for all $x \in \bar{\Omega}$.

Proof.

The kernel of the Dirichlet operator formally is given by an equality [3]:

$$
\operatorname{ker} D(x, y)=\sum_{t=1}^{\infty} u_{t}\left(q_{j}\right)(x) \overline{u_{t}\left(q_{j}\right)(y)} \cdot\left(\mu_{t}\left(q_{j}\right)-\lambda\right)^{-1}, x, y \in S
$$


where $\operatorname{ker} D\left(\lambda, q_{1}\right)-\operatorname{ker} D\left(\lambda, q_{2}\right)$ makes sense as an operator in $L_{2}(S \times S)$. Consider a difference

$$
\begin{gathered}
\operatorname{ker} D\left(\lambda, q_{1}\right)-\operatorname{ker} D\left(\lambda, q_{2}\right)= \\
=\sum_{t=1}^{\infty} u_{t}\left(q_{1}\right)(x) \overline{u_{t}\left(q_{1}\right)(y)} \cdot\left(\mu_{t}\left(q_{1}\right)-\lambda\right)^{-1}-\sum_{t=1}^{\infty} u_{t}\left(q_{2}\right)(x) \overline{u_{t}\left(q_{2}\right)(y)} \cdot\left(\mu_{t}\left(q_{2}\right)-\lambda\right)^{-1} .
\end{gathered}
$$

For the sequence defined by the equalities (2), we have

$$
\lim _{n \rightarrow \infty}\left\|D\left(l_{n}, q_{1}\right)-D\left(l_{n}, q_{2}\right)\right\| \cdot\left\|\frac{\partial \varphi_{l_{n}, \omega_{n}}}{\partial \nu}-\delta \varphi_{l_{n}, \omega_{n}}\right\|_{L_{2}(S)} \cdot\left\|\frac{\partial \varphi_{l_{n},-\theta_{n}}}{\partial \nu}-\delta \varphi_{l_{n},-\theta_{n}}\right\|_{L_{2}(S)}=0 .
$$

Therefore, using the equality (3), we claim that

$$
\lim _{n \rightarrow \infty}\left|F\left(l_{n}, \theta_{n}, \omega_{n} ; q_{1}\right)-F\left(l_{n}, \theta_{n}, \omega_{n} ; q_{2}\right)\right|=0 .
$$

And, therefore, $q_{1}(x)=q_{2}(x)$ for all $x \in \bar{\Omega}$. Indeed, then

$$
\int_{\Omega} \exp (-i x \cdot \xi) q_{1}(x) d x=\int_{\Omega} \exp (-i x \cdot \xi) q_{2}(x) d x .
$$

Thus, the potential of problem (1) is uniquely determined, if there is no a finite number of spectral data.

The validity of the mathematical model of recovery of potential (MRP) in the Robin problem follows from this theorem.

MRP 1. Let $\Omega$ - be bounded domain in $R^{N}(N \geq 2)$ with boundary $S$ of class $C^{\infty}$. Suppose that in the problem (1) the following values are known: a potential $q_{1}$, eigenvalues, with the exception, perhaps, of a finite set of them, and values of eigenfunctions on the boundary $S$. Suppose that the following conditions holds for problem (1) with potential $q_{2}$ :

1. $\left.\forall t \in N U_{t}\left(q_{1}\right)\right|_{S}=\left.U_{t}\left(q_{2}\right)\right|_{S}$;

2. $\exists T \geq P \forall t \geq T \mu_{t}\left(q_{1}\right)=\mu_{t}\left(q_{2}\right)$,

then for all $x$ from $\bar{\Omega}$ an equality $q_{1}(x)=q_{2}(x)$ holds.

\section{Theorem about the Uniqueness of the Recovery of Potential, when the Character of the Asymptotic Expansion of Eigenvalues is Known}

Suppose that for $t \rightarrow \infty$ the eigenvalues of problem (1) have the asymptotic

$$
\mu_{t}=C_{1} \cdot t^{2 / N}+o\left(t^{1 / N+\gamma}\right), \text { where } 0<\gamma<\frac{1}{N}, C_{1}>0 .
$$

In this case, the following statement holds [4]:

for $\left|n-t_{k}\right|>C \cdot t_{k}^{\beta}>0$, where $1-\frac{1}{N}<\beta \leq 1$, we have

$$
\begin{aligned}
& \left|\mu_{n}\left(q_{j}\right)-\mu_{t_{k}}\left(q_{j}\right)\right| \geq \text { const } \cdot \max \left\{t_{k}, n\right\}^{\beta}>0, \\
& \left|\mu_{n}\left(q_{1}\right)-\mu_{t_{k}}\left(q_{2}\right)\right| \geq \text { const } \cdot \max \left\{t_{k}, n\right\}^{\beta}>0 .
\end{aligned}
$$


Let natural $t_{0}$ be such that $\mu_{t_{0}}\left(q_{1}\right)=\mu_{t_{0}}\left(q_{2}\right)$. We set $l_{n_{0}}=n_{0}^{2}-1+2 n_{0} i$, where $n_{0}=\left[\sqrt{\mu_{t_{0}}\left(q_{1}\right)-1}\right]$. For potential $q \in C^{\infty}(\bar{\Omega})$ of problem (1) an estimate is obtained [14]:

$$
\left\|u_{t}(q)\right\|_{L_{2}(S)} \leq C_{0}\left|\mu_{t}(q)\right|^{\frac{N}{4}}
$$

Let us consider potentials $q_{1}, q_{2}$, such that the more stringent conditions for them hold, for example, in two dimension case:

$$
\left\|u_{t}\left(q_{j}\right)\right\|_{L_{2}(S)} \leq C_{4} t^{\frac{1}{N}}, C_{4}>0
$$

We estimate the operator norm

$$
\begin{gathered}
\left\|\operatorname{ker} D\left(\lambda, q_{1}\right)-\operatorname{ker} D\left(\lambda, q_{2}\right)\right\| \leq \\
\leq \sum_{t=1}^{\infty}\left|\mu_{t}\left(q_{2}\right)-\mu_{t}\left(q_{1}\right)\right| \cdot\left|\mu_{t}\left(q_{1}\right)-\lambda\right|^{-1} \cdot\left|\mu_{t}\left(q_{2}\right)-\lambda\right|^{-1} \cdot\left\|u_{t}\left(q_{1}\right)(x)\right\|_{L_{2}(S)}^{2}+ \\
+\sum_{t=1}^{\infty}\left\|u_{t}\left(q_{1}\right)(x) \cdot \overline{u_{t}\left(q_{1}\right)(y)}-u_{t}\left(q_{2}\right)(x) \cdot \overline{u_{t}\left(q_{2}\right)(y)}\right\|_{L_{2}(S \times S)} \times\left|\mu_{t}\left(q_{2}\right)-\lambda\right|^{-1} \equiv S_{1}+S_{2} .
\end{gathered}
$$

Suppose that for $\varepsilon>1+\frac{4}{3 N}$ the condition

$$
p_{0}=\varlimsup_{t \rightarrow \infty} t^{\varepsilon}\left|\mu_{t}\left(q_{2}\right)-\mu_{t}\left(q_{1}\right)\right|<\infty
$$

is true. Then from (7) we get

$$
\begin{gathered}
S_{1} t_{0}^{2 / N} \leq \text { const } \sum_{t=1}^{\infty} \frac{\left|\mu_{t}\left(q_{1}\right)-\mu_{t}\left(q_{2}\right)\right| t^{\frac{2}{N}} t_{0}^{2 / N}}{\left|\mu_{t}\left(q_{1}\right)-\mu_{t_{0}}\left(q_{1}\right)-2 n i\right| \cdot\left|\mu_{t}\left(q_{2}\right)-\mu_{t_{0}}\left(q_{1}\right)-2 n i\right|} \equiv \\
\equiv \sum_{\left|t-t_{0}\right| \leq C_{2} \cdot t_{0}^{\beta}}+\sum_{\left|t-t_{0}\right| \geq C_{2} \cdot t_{0}^{\beta}>0} .
\end{gathered}
$$

One can evaluate each sum, using $(7)-(10)$, and show $\lim _{t_{0} \rightarrow \infty} S_{1} t_{0}^{\frac{2}{N}}=0$.

Consider sum $S_{2}$. Suppose that for $\delta>1+\frac{1}{2 N}$ the condition

$$
\varlimsup_{t \rightarrow \infty} t^{\delta}\left\|u_{t}\left(q_{1}\right)(x) \overline{u_{t}\left(q_{1}\right)(y)}-u_{t}\left(q_{2}\right)(x) \overline{u_{t}\left(q_{2}\right)(y)}\right\|_{L_{2}(S \times S)}<\infty
$$

holds. Similarly we get that $\lim _{t_{0} \rightarrow \infty} S_{2} t_{0}^{\frac{2}{N}}=0$. Therefore (4) holds. Therefore, we claim that the functions $q_{1}$ and $q_{2}$ equal for all $x$ from $\bar{\Omega}$.

The following theorem follows from all stated above.

Theorem 2. Suppose that in Robin problems (1) the potentials $q_{1}$ and $q_{2}$ in $\bar{\Omega}$ such that

$$
\begin{gathered}
\mu_{t}\left(q_{j}\right)=C_{1} \cdot t^{2 / N}+o\left(t^{\frac{1}{N}+\gamma}\right), 0<\gamma<\frac{1}{N}, C_{1}>0 \\
\left\|u_{t}\left(q_{j}\right)\right\|_{L_{2}(S)} \leq C_{2} \cdot t^{1 / N}, C_{2}>0, \quad(j=1,2) .
\end{gathered}
$$


Suppose $\varepsilon>1+\frac{4}{3 N}$ and $\delta>1+\frac{1}{2 N}$ such that

$$
\begin{gathered}
\varlimsup_{t \rightarrow \infty} t^{\varepsilon}\left|\mu_{t}\left(q_{2}\right)-\mu_{t}\left(q_{1}\right)\right|<\infty, \\
\varlimsup_{t \rightarrow \infty} t^{\delta}\left\|u_{t}\left(q_{1}\right)(x) \overline{u_{t}\left(q_{1}\right)(y)}-u_{t}\left(q_{2}\right)(x) \overline{u_{t}\left(q_{2}\right)(y)}\right\|_{L_{2}(S \times S)}<\infty
\end{gathered}
$$

exist. Then $q_{1}$ and $q_{2}$ coincide everywhere on $\bar{\Omega}$.

On the basis of this theorem we have the following

MRP 2. Let $\Omega$ be bounded domain in $R^{N}(N \geq 2)$ with boundary $S$ of class $C^{\infty}$. Let in problem (1) the potential $q_{1}$ is known and conditions

$$
\begin{gathered}
\mu_{t}\left(q_{1}\right)=C_{1} \cdot t^{2 / N}+o\left(t^{\frac{1}{N}+\gamma}\right), 0<\gamma<\frac{1}{N}, C_{1}>0 \\
\left\|u_{t}\left(q_{1}\right)\right\|_{L_{2}(S)} \leq C_{2} \cdot t^{1 / N}, C_{2}>0
\end{gathered}
$$

hold. Suppose that for problem (1) with potential $q_{2}$ the conditions

$$
\begin{gathered}
\mu_{t}\left(q_{2}\right)=C_{1} \cdot t^{2 / N}+o\left(t^{\frac{1}{N}+\gamma}\right), 0<\gamma<\frac{1}{N}, C_{1}>0 \\
\left\|u_{t}\left(q_{2}\right)\right\|_{L_{2}(S)} \leq C_{2} \cdot t^{1 / N}, C_{2}>0
\end{gathered}
$$

hold, there exist $\varepsilon>1+\frac{4}{3 N}$ and $\delta>1+\frac{1}{2 N}$, such that

$$
\begin{gathered}
\varlimsup_{t \rightarrow \infty} t^{\varepsilon}\left|\mu_{t}\left(q_{2}\right)-\mu_{t}\left(q_{1}\right)\right|<\infty, \\
\varlimsup_{t \rightarrow \infty} t^{\delta}\left\|u_{t}\left(q_{1}\right)(x) \overline{u_{t}\left(q_{1}\right)(y)}-u_{t}\left(q_{2}\right)(x) \overline{u_{t}\left(q_{2}\right)(y)}\right\|_{L_{2}(S \times S)}<\infty .
\end{gathered}
$$

Then $q_{1}$ and $q_{2}$ coincide everywhere on $\bar{\Omega}$.

\section{Conclusion}

We obtained the theorems about the uniqueness of the recovery of potential for the inverse Borg - Levinson problem with boundary Robin conditions by incomplete spectrum with a given asymptotics. Models of recovery of potential were formulated on the basis of presented theorems. Further development of this problem may be the proof of theorems about the uniqueness of recovery of potential by incomplete spectrum, when there exist no an infinite number of spectral data, the more so that this quastion was already considered for the problem with the Dirichlet boundary conditions. It should focus on the theorems about existence.

\section{References}

1. Belishev M.I. An Approach to Multidimensional Inverse Problems for the Wave Equation. Doklady Akademii Nauk SSSR, 1987, vol. 297, no. 3, pp. 524-527. (in Russian) 
2. Berezanskii Y.M. On the Inverse Problem of Spectral Analysis for the Schrodinger Equation. Doklady Akademii Nauk SSSR, 1955, vol. 105, no. 2, pp. 197-200. (in Russian)

3. Dubrovskii V.V. A Theorem about the Uniqueness of the Solution of Inverse Problems of Spectral Analysis. Differentsial'nye uravneniya [Differential Equations], 1997, vol. 33, no. 3, pp. 421-422. (in Russian)

4. Dubrovskii V.V., Pechentsov A.S. The Asymptotic Behavior of the Spectral Function of Self-Adjoint Pseudodifferential Operators. Differentsial'nye uravneniya [Differential Equations], 1993, vol. 29, no. 5, pp. 852-858. (in Russian)

5. Isozaki H. Some Remarks on the Multidimensional Borg - Levinson Theorem. Journal of Mathematics of Kyoto University, 1991, vol. 31, no. 3, pp. 743-753.

6. Kadchenko S.I., Kakushkin S.N. The Numerical Methods of Eigenvalues and Eigenfunctions of Perturbed Self-Adjoin Operator Finding. Bulletin of the South Ural State University. Series: Mathematical Modelling, Programming and Computer Software, 2012, no. 27 (286), pp. 45-57. (in Russian)

7. Kadchenko S.I., Kakushkin S.N. Calculation of Values of Eigenfunctions of Discrete Semibounded from Below Operators via the Method of Regularized Traces. Vestnik Samarskogo gosudarstvennogo universiteta. Estestvennonauchnaya seriya, 2012, no. 6 (97), pp. 13-21. (in Russian)

8. Kakushkin S.N. Mathematical Modelling of Finding the Values of Eigenfunctions for the Electrical Oscillations in the Extended Line Problem Using the Method of Regularized Traces. Bulletin of the South Ural State University. Series: Mathematical Modelling, Programming and Computer Software, 2013, vol. 6, no. 3, pp. 125-129. (in Russian)

9. Kadchenko S.I., Kakushkin S.N. Meaning of the First Eigenfunctions of Perturbed Discrete Operators with Simple Spectrum Finding. Bulletin of the South Ural State University. Series: Mathematical Modelling, Programming and Computer Software, 2012, no. 5 (264), pp. 25-32. (in Russian)

10. Kadchenko S.I., Kakushkin S.N. The Algorithm for Finding of Meanings of Eigenfunctions of Perturbed Self-Adjoint Operators via Method Regularized Traces. Bulletin of the South Ural State University. Series: Mathematical Modelling, Programming and Computer Software, 2012, no. 40 (299), pp. 83-88. (in Russian)

11. Kadchenko S.I. Method of Regularized Traces. Bulletin of the South Ural State University. Series: Mathematical Modelling, Programming and Computer Software, 2009, no. 37 (170), pp. 4-23. (in Russian)

12. Nachman F., Sylvester J., Uhlmann G. An n-Dimensional Borg - Levinson Theorem. J. Math. Phys., 1988, vol. 115, pp. 595-605.

13. Sadovnichii V.A., Dubrovskii V.V., Smirnova L.V. Uniqueness of Solutions to Inverse Eigenvalue Problems. Doklady Akademii Nauk, 2000, vol. 61, no. 1, pp. 67-69. (in Russian)

14. Smirnova L.V. Evaluation of Module of Eigenfunctions of Robin Problem for a SelfAdjoint Operator. Elektromagnitnye volny $i$ elektronnye systemy [Electromagnetic Waves and Electronic Systems], 1999, vol. 4, no. 6, pp. 15-17. (in Russian) 
15. Smirnova L.V. On the Question of a Mathematical Model of a Recovery of Smooth Potentials in the Inverse Dirichlet Problem for the 2-Dimensional and 3-Dimensional Cases. Mathematical Support and Software for Systems in Industrial and Social Spheres. - Magnitogorsk: Nosov Magnitogorsk State Technical University, 2012, pp. 57-66. (in Russian)

16. Dubrovskii V.V., Smirnova L.V. On Reconstruction of the Potential in the Inverse Robin Problem. News of Higher Educational Institutions. Mathematics, 2002, no. 7 (482), pp. 8-13. (in Russian)

17. Dubrovskii V.V., Smirnova L.V. The Uniqueness of Solution of Inverse Problems of Spectral Analysis for Equations of Mathematical Physics. Fundamental and Applied Mathematics, 1999, vol. 5, no. 2, pp. 411-416. (in Russian)

18. Smirnova L.V. On the Question of a Mathematical Model of the Recovery of Smooth Potentials in the Inverse Dirichlet Problem for the $n$-Dimensional Case. Mathematical Support and Software for Systems in Industrial and Social Spheres, 2013, no. 1 (3), pp. 11-17. (in Russian)

19. Smirnova L.V. Matematicheskaya model' vosstanovleniya gladkikh potentsialov v obratnykh zadachakh spektral'nogo analiza [Mathematical Model of Recovery of Smooth Potentials in Inverse Problems of Spectral Analysis. Dissertation of the Candidate of Physical and Mathematical Sciences]. Chelyabinsk, 2002. (in Russian)

20. Smirnova L.V., Torshina O.A. Infinite Sequences not Affecting the Unique Recovery of the Potential. Applied and Fundamental Studies: Proceedings of the 4th International Academic Conference. November 29-30, 2013, St. Louis, USA. Publishing House Science and Innovation Center, 2013.

Larisa V. Smirnova, candidate of physical and mathematical sciences, associate professor, department of Mathematics 1, Nosov Magnitogorsk State Technical University, Magnitogorsk, Russian Federation, smirnova20@bk.ru.

Received November 15, 2015

УДК 519.642.8

DOI: $10.14529 /$ jcem 150408

ИССЛЕДОВАНИЕ ВОПРОСА ЕДИНСТВЕННОСТИ ВОССТАНОВЛЕНИЯ ПОТЕНЦИАЛА ПО СПЕКТРУ

В ОБРАТНОЙ ЗАДАЧЕ БОРГА - ЛЕВИНСОНА

С КРАЕВЫМИ УСЛОВИЯМИ РОБЕНА

\section{Л.В. Смирнова}

В статье рассматривается обратная задача Борга - Левинсона с краевыми условиями Робена, для которой формулируются условия единственности восстановления потенциала по спектру. Подобная задача, но с краевыми условиями Дирихле, достаточно полно изучена. Известно, что можно отбросить конечное число спектральных 


\begin{abstract}
данных в обратной задаче Борга - Левинсона с краевыми условиями Дирихле и это не влияет на единственность восстановления потенциала. В представленной статье доказывается, что теорема, полученная для краевых условий Дирихле, справедлива и для задачи с краевыми условиями Робена. Для этого доказываются теоремы единственности восстановления потенциала в обратной задаче Борга - Левинсона краевыми условиями Робена, дается ответ на вопрос, в каком случае данная задача имеет единственное решение, если известен характер асимптотического разложения ее собственных чисел. На основе этого предложен подход к созданию математической модели восстановления потенциала в обратной задаче Робена.
\end{abstract}

Ключевые слова: обратнал задача Борга - Левинсона; собственные числа; собственные функции; краевые условия Робена.

\title{
Литература
}

1. Белишев, М.И. Об одном подходе к многомерным обратным задачам для волнового уравнения / М.И. Белишев // ДАН СССР. - 1987. - Т. 297, № 3 . - С. 524-527.

2. Березанский, Ю.М. Об обратной задаче спектрального анализа для уравнения Шредингера / Ю.М. Березанский // ДАН СССР. - 1955. - Т. 105, № 2. C. $197-200$.

3. Дубровский В.В. Теорема о единственности решения обратных задач спектрального анализа / В.В. Дубровский // Дифференциальные уравнения. - 1997. - Т. 33, № 3. - C. 421-422.

4. Дубровский, В.В. Об асимптотике спектральной функции самосопря-женных псевдодифференциальных операторов / В.В. Дубровский, А.С. Печенцов // Дифференциальные уравнения. - 1993. - Т. 29, № 5. - С. 852-858.

5. Isozaki H. Some Remarks on the Multidimensional Borg - Levinson Theorem / H. Isozaki // Journal of Mathematics of Kyoto University. - 1991. - V. 31, № 3. - P. 743-753.

6. Кадченко, С.И. Численные методы нахождения собственных чисел и собственных функций возмущенных самосопряженных операторов / С.И. Кадченко, С.Н. Какушкин // Вестник ЮУрГУ. Серия: Математическое моделирование и программирование. - 2012. - № 27 (286), вып. 13. - С. 45-57.

7. Кадченко, С.И. Вычисление значений собственных функций дискретных полуограниченных снизу операторов методом регуляризованных следов / С.И. Кадченко, С.Н. Какушкин // Вестник СамГУ. Естественнонаучная серия. - 2012. № 6 (97). - C. 13-21.

8. Какушкин, С.Н. Математическое моделирование спектральной задачи об электрических колебаниях в протяженной линии методом регуляризованных следов / С.Н. Какушкин // Вестник ЮУрГУ. Серия: Математическое моделирование и программирование. - 2013. - Т. 6, № 3. - С. 125-129.

9. Кадченко, С.И. Нахождение значений первых собственных функций возмущенных дискретных операторов с простым спектром / С.И. Кадченко, С.Н. Какушкин // Вестник ЮУрГУ. Серия: Математическое моделирование и программирование. - 2012. - № 5 (264), вып. 11. - С. 25-32. 
10. Кадченко, С.И. Алгоритм нахождения значений собственных функций возмущенных самосопряженных операторов методом регуляризованных следов / С.И. Кадченко, С.Н. Какушкин // Вестник ЮУрГУ. Серия: Математическое моделирование и программирование. - 2012. - № 40 (299), вып. 14. - С. 83-88.

11. Кадченко, С.И. Метод регуляризованных следов / С.И. Кадченко // Вестник ЮУрГУ. Серия: Математическое моделирование и программирование. - 2009. № 37 (170), вып. 4. - С. 4-23.

12. Nachman, F. An n-Dimensional Borg - Levinson Theorem / F. Nachman, J. Sylvester, G. Uhlmann // Journal of Mathematical Physics. - 1988. - V. 115. - P. 595-605.

13. Sadovnichii, V.A. Uniqueness of Solutions to Inverse Eigenvalue Problems V.A. Sadovnichii, V.V. Dubrovskii, L.V. Smirnova // Doklady Mathematics. - 2000. V. 61, № 1. - P. 67-69.

14. Смирнова, Л.В. Оценка модуля собственных функций задачи Робина для самосопряженного оператора / Л.В. Смирнова // Электромагнитные волны и электронные системы. - 1999. - Т. 4, № 6. - С. 15-17.

15. Смирнова, Л.В. К вопросу о математической модели восстановления гладких потенциалов в обратной задаче Дирихле для 2-мерного и 3-мерного случаев / Л.В. Смирнова // Математическое и программное обеспечение систем в промышленной и социальной сферах. - Магнитогорск: Изд-во Магнитогорск. техн. ун-та, 2012. - C. 57-66.

16. Дубровский, В.В. К вопросу о восстановлении потенциала в обратной задаче Робена / В.В. Дубровский, Л.В. Смирнова // Известия высших учебных заведений. Математика. - 2002. - № 7 (482). - С. 8-13.

17. Дубровский, В.В. К единственности решения обратных задач спектрального анализа для уравнений математической физики / В.В. Дубровский, Л.В. Смирнова // Фундаментальная и прикладная математика. - 1999. - Т. 5, № 2. C. $411-416$.

18. Смирнова, Л.В. К вопросу о математической модели восстановления гладких потенциалов в обратной задачи Дирихле для $n$-мерного случая / Л.В. Смирнова // Математическое и программное обеспечение систем в промышленной и социальной сферах. - 2013. - № 1 (3). - С. 11-17.

19. Смирнова, Л.В. Математическая модель восстановления гладких потенциалов в обратных задачах спектрального анализа: дисс. ... канд. физ.-мат. наук. Л.В. Смирнова. - Челябинск, 2002.

20. Smirnova, L.V. Infinite Sequences not Affecting the Unique Recovery of the Potential / L.V. Smirnova, O.A. Torshina // Applied and Fundamental Studies: Proceedings of the 4th International Academic Conference. November 29-30, 2013, St. Louis, USA. Publishing House Science and Innovation Center. - St. Louis, 2013.

Смирнова Лариса Викторовна, кандидат физико-математических наук, доцент, кафедра высшей математики 1, Магнитогорский государственный технический университет им. Г.И. Носова (г. Магнитогорск, Российская Федерачия), smirnova20@bk.ru.

Поступила в редакиию 15 ноября 2015. 